\title{
Zebrafish as an innovative model for neuroendocrine tumors
}

\author{
Giovanni Vitale ${ }^{1,2}$, Germano Gaudenzi', Alessandra Dicitore ${ }^{2}$, Franco Cotelli ${ }^{3}$, \\ Diego Ferone ${ }^{4}$ and Luca Persani, ${ }^{1,2}$ \\ ${ }^{1}$ Department of Clinical Sciences and Community Health (DISCCO), University of Milan, Milan, Italy \\ ${ }^{2}$ Laboratory of Endocrine and Metabolic Research, Istituto Auxologico Italiano IRCCS, via Zucchi 18, \\ Cusano Milanino (MI) 20095, Italy \\ ${ }^{3}$ Department of Biosciences, University of Milan, Milan, Italy \\ ${ }^{4}$ Endocrinology Unit, Department of Internal Medicine and Medical Specialties, Center of Excellence for Biomedical \\ Research, IRCCS AOU San Martino-IST, University of Genoa, Genoa, Italy
}

\author{
Correspondence \\ should be addressed \\ to $G$ Vitale \\ Email \\ giovanni.vitale@unimi.it
}

\begin{abstract}
Tumor models have a relevant role in furthering our understanding of the biology of malignant disease and in preclinical cancer research. Only few models are available for neuroendocrine tumors (NETs), probably due to the rarity and heterogeneity of this group of neoplasms. This review provides insights into the current state-of-the-art of zebrafish as a model in cancer research, focusing on potential applications in NETs. Zebrafish has a complex circulatory system similar to that of mammals. A novel angiogenesis assay based on the injection of human NET cell lines (TT and DMS79 cells) into the subperidermal space of the zebrafish embryos has been developed. Proangiogenic factors locally released by the tumor graft affect the normal developmental pattern of the subintestinal vessels by stimulating the migration and growth of sprouting vessels toward the implant. In addition, a description of the striking homology between zebrafish and humans of molecular targets involved in tumor angiogenesis (somatostatin receptors, dopamine receptors, mammalian target of rapamycin), and currently used as targeted therapy of NETs, is reported.
\end{abstract}

\author{
Key Words \\ - zebrafish \\ - neuroendocrine tumors \\ - tumor xenografts \\ - angiogenesis \\ - somatostatin receptors
}

\section{Introduction}

In the past decades zebrafish (Danio rerio) has emerged as a powerful vertebrate model system to study vertebrate developmental mechanisms. Indeed, zebrafish has a high fecundity (a female can lay up to 100-200 eggs/week), the embryos develop outside the body and are transparent, facilitating the observation of morphogenetic movements and organogenesis in real time (Pistocchi et al. 2008, Bellipanni et al. 2010, Quaife et al. 2012).

More recently, the zebrafish has become an attractive model for the research on several human diseases including cancer (Liu \& Leach 2011, Malafoglia et al. 2013). Although there are evident structural and physiological differences between zebrafish and humans, the zebrafish provides several advantages when compared with other vertebrate model systems (Lieschke \& Currie 2007, Fieramonti et al. 2012, Konantz et al. 2012, Santoriello \& Zon 2012).

This review provides insights into the current stateof-the-art of zebrafish as a model in cancer research, focusing on potential applications in neuroendocrine tumors (NETs).

\section{Zebrafish as a cancer model}

Although fish do not have certain organs found in mammals (breast, prostate, and lung), zebrafish spontaneously develops almost any type of tumor (Nicoli et al.

Published by Bioscientifica Ltd. 
2007). In addition, there is a high degree of histological similarity between tumors developed in zebrafish and those in human and many aspects of carcinogenesis are conserved in fish as compared with humans (Amatruda et al. 2002). In fact, despite zebrafish diverged from mammals during evolution about 450 million years ago, the developmental and genetic programs between these organisms are largely conserved (Liu et al. 2002).

Several strategies have been used to generate cancer models and to identify cancer-related genes in zebrafish: treatment with chemical carcinogens, forward genetic screening, reverse genetic approaches, transgenic models, and xenotransplantation of mammalian cancer cells (Tobia et al. 2011, Shive 2013).

Like their human and murine counterparts, zebrafish are susceptible to develop a significant number and wide variety of neoplasms after the exposure to chemical carcinogens (Feitsma \& Cuppen 2008). Treating fish with carcinogens is very easy to set-up because the watersoluble carcinogens can be added to the fish water and embryos, larvae, and adult animals can be exposed for longer time periods (Feitsma \& Cuppen 2008). Although the routes of exposure to carcinogens may differ between fish and mammalians, the liver is the primary target for many carcinogens in both fish and rodents (Shive 2013).

Zebrafish is one of the best vertebrate model currently used for forward genetic screening in order to identify cancer susceptibility genes. Mutations are induced in the zebrafish genome by carcinogens, irradiation, or viral/ transposon-based vectors (insertional mutagenesis). The progeny of mutagenized fish are screened for cancer phenotypes. Mutated genes are identified through genetic mapping, sequencing analysis, and phenotype validation (Liu \& Leach 2011). A forward chemical screen using zebrafish embryos may provide an alternative approach to identify cancer-susceptibility genes during embryogenesis, considering that several cellular pathways involved in cancer play also a role in embryonic development (Liu \& Leach 2011). In addition, zebrafish forward-genetic screens are simplified by the optical transparency of embryos and larvae, a feature that facilitates the screening for cancer phenotype without sophisticated equipments (Lieschke \& Currie 2007).

Reverse genetics is another strategy consisting in the modification of a gene of interest, or its expression, to analyze the phenotypic effects. The genetic versatility of zebrafish system and the recent technological innovations in genetics have transformed zebrafish into a sophisticated reverse genetic system, offering the possibility to increase our knowledge in the field of cancer. Several approaches are used to evaluate the effect of specific gene mutations on cancer development.

Targeting Induced Local Lesions in Genomes (TILLING) is a technique, in which genomic DNA from a large library of ethylnitrosourea-mutagenized zebrafish are screened for specific mutations in genes of interest. Screening is performed by PCR amplification of specific exons from each mutagenized zebrafish followed by mutation detection through direct resequencing of PCR fragments or alternatively, by CEL1 endonucleasemediated mutation discovery (Liu \& Leach 2011, Shive 2013). Once a mutant of interest is identified, individuals isolated from the library and mutant lines are established (Moens et al. 2008). The rapid advancements in next generation sequencing platforms, able to increase the speed and to reduce the cost of DNA sequencing, have recently increased the efficiency of mutation discovery for TILLING from mutant libraries (Santoriello \& Zon 2012). However, this technique is laborious and time-consuming for a regular laboratory. Therefore, the Sanger Institute has set up a project called 'Zebrafish Mutation Project (ZMP)' with the aims to create a knockout allele in every protein coding gene in the zebrafish genome, using a combination of whole-exome enrichment and Illumina next generation sequencing. Mutations for 11892 genes (about 45\% of all zebrafish genes) have been identified by this project so far (http://www.sanger.ac.uk/Projects/D_rerio/zmp/).

Several emerging technologies are currently able to create targeted knockout mutants in zebrafish, such as zinc-finger nuclease-targeted mutagenesis, transcription activator-like effector nucleases (TALENs), and the clustered regularly interspaced short palindromic repeats (CRISPR)-Cas (CRISPR-associated proteins) system. Zinc finger endonucleases consist of a DNA-binding zinc finger protein fused to a nonspecific cleavage domain of the FokI endonuclease. They can induce double-strand breaks that are generated by FokI endonuclease upon binding to specific DNA sequences recognized by the zinc-finger motifs. These damages are imprecisely repaired by nonhomologous end joining a DNA repair pathway frequently causing small insertions or deletions at the break site. Therefore, engineered zinc-finger nucleases can be designed to deliver frameshift mutations at specific sites in the genome of the zebrafish (Liu \& Leach 2011, Santoriello \& Zon 2012, Shive 2013).

TALENs are important new tools for genome engineering. TALENs are chimeric nucleases generated by a transcription activator-like (TAL) effector DNA-binding domain, constructed to bind any desired DNA sequence fused to a DNA cleavage domain. This system enables

Published by Bioscientifica Ltd. 
targeted gene disruption in a wide variety of model organisms, is easier to design and assemble compared with zinc-finger nucleases (Santoriello \& Zon 2012, Shive 2013). Recent works have reported that TALENs can induce mutations in endogenous zebrafish genes, showing a high efficiency in inducing locus-specific DNA breaks in somatic and germline tissues (at some loci this efficacy approaches 100\%) (Bedell et al. 2012, Ma et al. 2013).

Another innovative system for targeted genome engineering derived from the CRISPR-Cas defense. CRISPR-Cas constitutes an adaptive immune system used by bacteria and archaea against invading foreign nucleic acids derived from bacteriophages or exogenous plasmids. This defense system can incorporate specific short sequences of foreign nucleic acids into a region of the host genome that is distinguished by CRISPR. When these sequences are transcribed and processed into small RNAs, they guide a multifunctional protein complex (Cas proteins) to recognize and destroy incoming foreign genetic elements in a sequence-specific manner (Bhaya et al. 2011). Bacterial type II CRISPR systems can be engineered to direct targeted double-stranded DNA breaks in vitro to specific sequences by using a single 'guide RNA' with complementarity to the DNA target site and a Cas9 nuclease in mammalian cells (Cong et al. 2013). This system also works efficiently in vivo for inducing targeted alterations into endogenous genes in zebrafish with a somatic targeting efficiency similar to those obtained using zincfinger nucleases and TALEN (Hwang et al. 2013).

A morpholino technology is routinely used in zebrafish to perform a transient gene knockdown. Morpholinos are synthetic antisense oligonucleotides which replace the ribose rings of RNA with morpholine rings. This modification enables morpholinos to be resistant to nuclease digestion and to increase binding activity to their complementary RNA sequences. Therefore, using a specific antisense morpholino, it is possible to target a selected transcript and to dramatically reduce the levels of the corresponding functional protein (Bill et al. 2009). Nevertheless, once injected into the embryos, the effect of morpholinos lasts only few days and thus this technique is not suitable for the study of loss-of-function consequences beyond the larval period.

Transgenic animals have provided the tools for exploring the effects of oncogene overexpression or tumor-suppressor gene inactivation (via dominantnegative strategies) on tumor phenotype. Several transgenic zebrafish models of cancer have been developed by microinjection of specific mammalian oncogenes in early-stage zebrafish embryos using transposon-mediated systems, supporting that most of tumorigenic mechanisms are conserved from zebrafish to human (Lieschke \& Currie 2007). Injection of foreign DNA into fertilized eggs results in germline transgene integration with a high efficiency. Interestingly, tissue-specific and/or inducible transgenic methods have been successfully used in zebrafish to induce a specific type of cancer and to regulate the timing of tumor initiation. Indeed, different tissue-specific promoters and systems able to regulate gene expression with a high degree of temporal and spatial precision have been adopted in zebrafish, such as Tol2 transposon and the mifepristone-inducible LexPR, GAL4UAS, and Cre-LoxP systems (Santoriello \& Zon 2012, Mimeault \& Batra 2013). In this frame, transgenic animals have led to experiments probing overexpression of WT, constitutively active, or dominant negative versions of a gene of interest (Santoriello \& Zon 2012).

Xenotransplantation of human or mouse cancer cells into zebrafish represents another interesting tool mainly devoted to study in vivo tumor angiogenesis, invasiveness, and metastatic dissemination (Nicoli et al. 2007).

Although murine xenotransplant model remains the gold standard for studies in the field of human cancer research and drug development, there are several limitations associated with this model: long duration of time required to have a visible tumor implant and to perform experiments (from several weeks to months); requirement of a skilled technician for the complexity of several procedures; immunosuppressed mice are required to avoid transplant rejection, these animals are more susceptible to infection and drug toxicity than normal mice and need specific housing and care; its laborious and time-consuming process makes this model very expensive; large number of cells (about 1 million) are required to generate a tumor, making it less suitable as a xenotransplant model using primary tumor cells; high difficulties to generate mouse xenotransplant models able to metastasize (Haldi et al. 2006, Konantz et al. 2012).

The zebrafish xenotransplantation model cannot replace the use of mammalian model systems; however, it can overcome some of these drawbacks previously reported, providing a solid and complementary approach to mouse model. Experimental models have been established in zebrafish embryos, juveniles, and adults, each one with its own advantages and limits (Lieschke \& Currie 2007).

Zebrafish is an amenable model system for vascular biology studies. Indeed, vessel/emathopoietic genetic program is largely conserved during evolution. Furthermore, zebrafish embryos are so small that they can receive enough oxygen by passive diffusion to survive and

Published by Bioscientifica Ltd. 
develop, reasonably normally, for several days in the complete absence of blood circulation (Isogai et al. 2001).

In embryos, vessels formation can occur by two different processes, vasculogenesis and angiogenesis. During vasculogenesis, endothelial cells differentiate from mesodermal precursors and proliferate in situ within a previously avascular tissue to form a primitive tubular network. Angiogenic remodeling refers to the process by which this initial network is modified to form the mature vasculature. In particular, angiogenesis occurs in the formation of the intersomitic vessels (ISVs) of the trunk, that sprout from the dorsal aorta, as well as of subintestinal vessels (SIV) originating from the duct of Cuvier area (Fig. 1A and B; Isogai et al. 2001). A further vessel present in this region is the common cardinal vein $(\mathrm{CCV})$ that fans out across the yolk on either side (Fig. 1A and B; Isogai et al. 2001). Moreover, zebrafish possess a lymphatic system that shares many of the morphological, molecular, and functional characteristics found in other vertebrates (Yaniv et al. 2006).

Due to its transparency and the use of transgenic zebrafish expressing green fluorescent protein (GFP) in endothelial lineages, zebrafish is an excellent animal model to study tumor angiogenesis and metastatic behavior of transplanted tumor cells, showing all the critical steps of the metastatic process by live imaging at high resolution, including breaching of the basement membrane, intravasation, extravasation, and colonization of distant metastatic sites (Taylor \& Zon 2009, Moore \& Langenau 2012). The generation of the Casper mutant (Wenner 2009), which remain completely transparent throughout life, has provided to use xenograft tumor model also in juvenile/adult fish.

Original studies have shown the feasibility of injecting human melanoma cells in zebrafish embryos to follow their fate and to study their impact on host development. Tumor cells were injected into 3-h old zebrafish blastula-stage embryos to explore potential bidirectional interactions between cancer cells and embryonic cells. When injected at this early stage of development, highly aggressive melanoma cells survive but do not cause cancer or metastases, while they are able to redirect normal embryonic development, promoting formation of a secondary embryonic axis, probably due to Nodal signaling from the tumor cells (Lee et al. 2005, Topczewska et al. 2006). These results indicate that developing zebrafish can be used as a biosensor for tumor-derived signals. However, grafting of tumor cells at this stage, well before vascular development, results in their reprograming toward a nontumorigenic phenotype, thus hampering any attempt to investigate tumor-driven vascularization.

The first successful study on tumor-induced angiogenesis in zebrafish has been performed by Haldi et al. (2006). They reported that transplanted WM-266-4 melanoma cells into the yolk of zebrafish at 48 hours post fertilization (hpf) rapidly proliferated, migrated, formed tumor-like

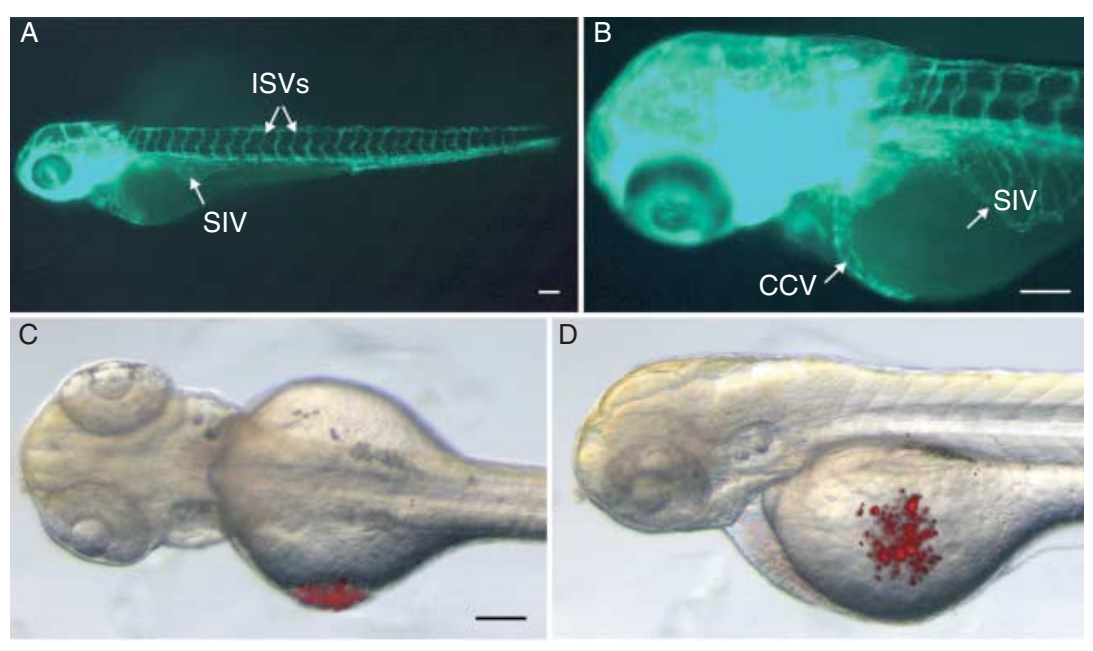

\section{Figure 1}

Human neuroendocrine tumor (NET) transplantation in zebrafish larvae. NET cells were injected in $48 \mathrm{hpf} T g\left(\right.$ fli1:EGFP ${ }^{y^{1}}$ zebrafish larvae that expresses EGFP in the vascular endothelium ( $A$ and $B$ ). Red stained NET cells (by Celltracker $\mathrm{Cm}$-Dil, Invitrogen) were grafted into the subepidermal space (between the periderm and the yolk syncytial layer) close to the
SIV plexus (C: dorsal view, D: lateral view). Pictures were taken with light and fluorescent illumination and digitally superimposed. CCV, common cardinal vein; ISVs, intersomitic vessels; SIV, subintestinal vessels. Scale bar, $100 \mu \mathrm{m}$. http://erc.endocrinology-journals.org DOI: 10.1530/ERC-13-0388
(C) 2014 Society for Endocrinology Printed in Great Britain
Published by Bioscientifica Ltd. 
masses, and stimulated angiogenesis through the recruitment of host endothelial cells and the formation of new vessels infiltrating the tumor mass.

Nicoli \& Presta (2007) and Nicoli et al. (2007) demonstrated a potent angiogenic response triggered by mammalian tumor cells injected in the proximity of the developing SIV plexus in zebrafish embryos at $48 \mathrm{hpf}$. Pro-angiogenic factors released locally by the tumor graft, including fibroblast growth factor (FGF) and vascular endothelial growth factor (VEGF), affect the normal developmental pattern of the SIV by stimulating the migration and growth of sprouting vessels toward the implant.

Marques et al. (2009) injected cells from gastrointestinal primary human tumors into the yolk sac of zebrafish embryos. Tumor cell invasion and micrometastasis formation were visible within 24 hours post-injection (hpi). Similar results were reported injecting highly metastatic murine melanoma B16-BL6 cells directly into the embryonic blood circulation in the ventral region of the duct of Cuvier. Tumor cells extravasated in different anatomical sites $24 \mathrm{hpi}$ and formed extravascular micrometastases during the next 3-4 days (Tobia et al. 2013).

Stoletov et al. (2007) transplanted several human cancer cells into the peritoneal cavity of chemically immunosuppressed translucent zebrafish. Cancer cells expressing the metastatic gene rhoC employ an amoeboid-type invasion and stimulated angiogenesis. This system, taking advantage of the development of translucent fish and high-resolution confocal microscopy, provided the opportunity to visualize tumor invasion and metastasis in a model where mature fish vasculature mimics tumor-induced angiogenesis in human patients.

Very recently, Rampazzo et al. (2013) have injected glioblastoma multiforme (GBM) cells into the brain of developing zebrafish larvae. By using a Wnt-reporter zebrafish strain, they targeted primary human GBM cell injection into a Wnt-rich brain site and found that activation of Wnt signaling promotes neuronal differentiation of GBM cells, thus restraining GBM aggressiveness.

Therefore, when compared with other in vivo tumor angiogenesis/invasion/differentiation assays, this zebrafish/tumor xenograft model presents several relevant advantages which are as follows (Nicoli \& Presta 2007, Tobia et al. 2011, 2013):

- Labeled tumor cells (e.g., GFP-transduced or fluorescent dye-loaded cells) can be easily visualized within the embryos, larvae, or Casper juvenile/adult fish. Because of the optical transparency and the availability of multiple zebrafish lines that express fluorescent proteins in normal tissues, zebrafish/tumor xenograft can provide a fast, high resolution on single-cell level and real-time monitoring of cell-stromal interactions and cancer progression in living animals (Konantz et al. 2012). The use of transgenic zebrafish, in which endothelial cells express GFP under the control of endothelial-specific promoters, represents an improvement of the zebrafish/tumor xenograft model, allowing the observation and time-lapse recording of newly formed blood vessels in live fish by epifluorescence microscopy as well as by in vivo confocal microscopy (Tobia et al. 2011). Several other available transgenic lines provide additional tools to study further aspects of the tumor-host interactions. For example, the use of transgenic zebrafish with neutrophils, macrophages, or platelets specifically labeled with fluorescent proteins, may improve our knowledge of the host inflammatory response against implanted tumors (Konantz et al. 2012, White et al. 2013).

- Immunohistochemistry and immunofluorescence staining can be performed on whole embryos and larvae or on histological sections to study protein expression and localization. Moreover, reverse transcriptasePCR analysis with species-specific primers allows the concomitant study of gene expression by grafted tumor cells and by the host (Nicoli \& Presta 2007, Tobia et al. 2011).

- Electron microscopy can be used in combination with light microscopy to perform detailed ultrastructural studies.

- As zebrafish at $48-72 \mathrm{hpf}$ do not have a fully developed immune system, no graft rejection occurs at this stage. Therefore, the xenotransplantation procedure does not require immune suppression at this stage of development. Although, the main advantage to use juvenile/adult zebrafish compared with embryos is that all the major organs including the vasculature have completed development and have reached their mature pattern, at these stages zebrafish has a functional immune system that must be suppressed with dexamethasone or irradiation for successful grafting of the cancer cells (Tobia et al. 2011).

- Zebrafish embryos are readily permeable to many different compounds dissolved in their culture media. In this frame, the zebrafish/tumor xenograft model represents a rapid and suitable test to screen small-molecules with potential antitumor activity and using a small amount of compounds (Pichler et al. 2003). Interestingly, several groups recently have developed in zebrafish embryos quantitative,

Published by Bioscientifica Ltd. 
automated, and short-term bio-imaging platforms to study angiogenesis/cancer dissemination and for the screening of anticancer drugs (Vogt et al. 2009, Ghotra et al. 2012).

- The required low number of implanted cells (50-1000 cells/embryo) may favor the use of tumor cells isolated from human primary culture in order to perform drug sensitivity testing for personalized cancer therapy. In addition, the model allows the continuous delivery of angiogenic factors from a very limited number of cells, mimicking the initial stages of tumor angiogenesis and metastasis.

- Zebrafish are not expensive and can be easily maintained in an aquarium with a minimal requirement of equipment and propagated in a large number due to their high rate of fecundity (Mimeault \& Batra 2013). The maintenance cost of zebrafish is considerably lower than that of mice (Pichler et al. 2003) and its logistic is much simpler than a mammalian facility.

- Transgenic reporter zebrafish lines can be used to track pathways involved in tumor-environment crosstalks (Moro et al. 2013, Rampazzo et al. 2013).

However, there are several disadvantages of using this model (Tobia et al. 2011, 2013), that need to be considered, such as:

- Species-specific microenvironmental differences may affect the behavior of grafted mammalian tumor cells and the lack of some mammalian organs in fishes (such as mammary gland, prostate, and lung) precludes the possibility to perform orthotopic transplantation experiments and to investigate tissue-specific mechanisms of tumor cell homing and colonization in these organs.

- Drug metabolism in zebrafish may be different from that in mammals.

- Zebrafish embryos are maintained at $28^{\circ} \mathrm{C}$. This may not represent an optimal temperature for mammalian cell growth and metabolism. However, the possibility to raise the incubation temperature up to $35^{\circ} \mathrm{C}$ with no apparent gross effects on zebrafish development has been reported (Haldi et al. 2006).

- Embryonic organs and systems are completely defined but their differentiation is incomplete.

- A limited number of antibodies against zebrafish proteins are available so far. Nevertheless, due to the high degree of molecular conservation in vertebrates, antibodies that target mammalian protein can be used to perform immunohistochemistry and immunofluorescence assays on zebrafish samples.

- As for other animal models, xenotransplantation requires good manual skills of the operator.

Therefore, the zebrafish/tumor xenotransplantation is considered as an attractive, robust, fast, and technically simple model to study tumor-host microenvironment and to screen for antiangiogenic compounds.

\section{Zebrafish as a cancer model for NETs}

Most of the players, pathways, and feedback loops of endocrine system are highly conserved from zebrafish to human (Bourque \& Houvras 2011, Lohr \& Hammerschmidt 2011). Orthologs for several mammalian neurohormones have been identified and localized in zebrafish (Toro et al. 2009, Lohr \& Hammerschmidt 2011). Therefore, the zebrafish is a relevant model for human endocrine system, providing important insights particularly into the development of endocrine glands (Porazzi et al. 2009).

Recent studies have suggested that zebrafish may emerge also as a new model of NETs with a reasonable prospect of success (Fig. 2).

Liu et al. (2011) generated a stable transgenic zebrafish (Tg:Pomc-Pttg) with overexpression of pituitary tumor transforming gene ( $p t t g$ ) targeted to the adenohypophyseal proopiomelanocortin (Pomc) cells. PTTG is overexpressed in more than $90 \%$ of pituitary tumors, including ACTH-secreting pituitary adenomas (Vlotides et al. 2007). Adult Tg:Pomc-Pttg fish developed pituitary corticotroph adenomas combined with pituitary cyclin $\mathrm{E}$ overexpression and metabolic disturbances, mimicking hypercortisolism caused by Cushing's disease. Although the chronic hypercortisolemic status was observed only in adult zebrafish, pituitary tumor was already detected within the first days of embryonic development. Like its mammalian counterpart, the Tg:Pomc-Pttg pituitary corticotroph adenoma developed cyclin E overexpression associated with G1/S phase disruption. This animal system has been adopted for an in vivo drug testing using several inhibitors of cyclin-dependent kinases (CDKs). R-roscovitine, a potent and selective inhibitor of CDK2/ cyclin E, specifically reversed corticotroph expansion in live Tg:Pomc-Pttg embryos. This effect was subsequently confirmed in a mouse model of corticotroph (Liu et al. 2011).

Germline mutations of the aryl hydrocarbon receptor interacting protein $(A I P)$ gene have been described in

Published by Bioscientifica Ltd. 




Currently available zebrafish models - Tg:Pomc-Pttg fish (Liu et al. 2011) - Usp39 mutants (Rios et al. 2011)

Promising zebrafish models

- Functional studies on zebrafish Aip gene



Currently available zebrafish models

- Overexpression of human MYCN and activated ALK genes in peripheral sympathetic nervous system (Zu et al. 2012)

von HIPPEL-LINDAU
(VHL) DISEASE

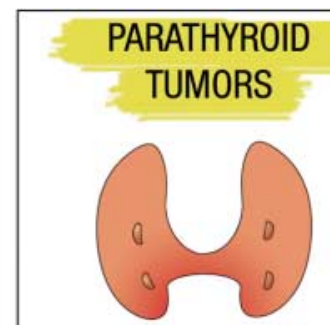

Promising zebrafish models - Cdc73 mutant


Currently available zebrafish models

- Stable mutant Nf1 zebrafish lines

(Shin et al. 2012)

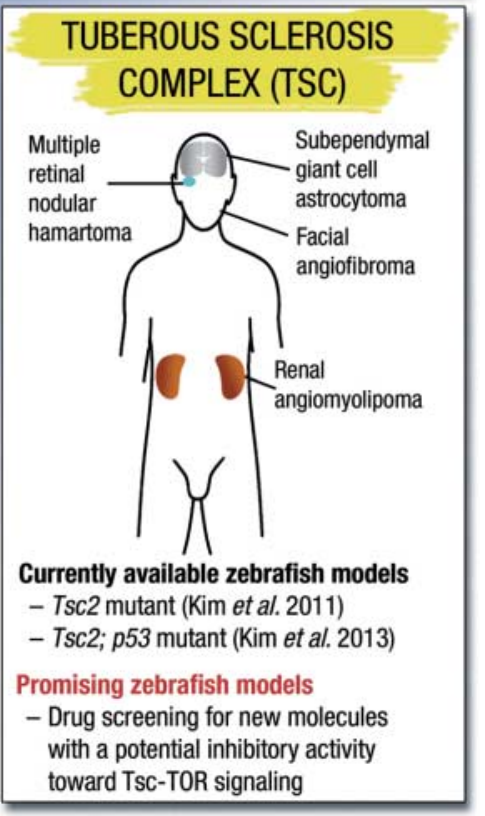

Figure 2

Currently available and promising zebrafish models to study neuroendocrine tumors (NETs).

http://erc.endocrinology-journals.org DOI: 10.1530/ERC-13-0388
() 2014 Society for Endocrinology Printed in Great Britain 
about $15-40 \%$ of familial cases of pituitary adenomas (Igreja et al. 2010). Equivalents of mammalian AIP are present and well conserved in the zebrafish. Studies on aip expression and functions in zebrafish are under investigation, offering a novel promising model to explore Aip protein interactions and to study pituitary tumorigenesis (Aflorei et al. 2012).

Other mechanisms potentially involved in pituitary tumorigenesis have been postulated through the use of the zebrafish model. By means of a forward genetic approach, Rios et al. (2011) identified a zebrafish ubiquitin-specific peptidase 39 (Usp39) mutant, developing a phenotype of microcephaly and pituitary hyperplasia. This study suggests that loss of usp39 results in aberrant retinoblastoma-1 mRNA splicing, which induces expression of its target $e 2 f 4$, a transcription factor involved in controlling the cell cycle and with oncogenic activity when overexpressed. Indeed, gene expression profiling of Usp39 mutants revealed a decrease in retinoblastoma- 1 and an increase in $e 2 f 4, r b l 2$ ( $p 130$ ), and $c d k n 1 a$ (p21) expression. These results disclose a new molecular mechanism, involving dysregulation of retinoblastoma and e2f4 pathways, responsible for pituitary tumorigenesis.

Although fish do not have anatomical structures corresponding to parathyroid glands, they express parathyroid hormone and calcium sensing receptor in gill tissue, both of them are functionally similar to their mammalian counterparts. Indeed, parathyroid gland and the gills of fish are evolutionarily related structures (Bourque \& Houvras 2011). In humans, germline inactivation of the HRPT2/CDC73 tumor suppressor gene, coding for parafibromin and discovered in the context of the hyperparathyroidism-jaw tumor (HPT-JT) syndrome, has been reported in 50-75\% of HPT-JT cases and in about $14 \%$ of familial isolated hyperparathyroidism (Carpten et al. 2002, Bricaire et al. 2013). In addition, HRPT2/CDC73 mutation is a common, somatic event in most parathyroid cancers and adenomas, underlining the relevant role of this gene in the pathogenesis of parathyroid tumors (Sharretts et al. 2010). However, most of the mechanisms through which HRPT2/CDC73 gene might control tissue-specific tumorigenesis are still unsolved. Interestingly, the zebrafish ortholog of $c d c 73$ has been identified in a genetic suppressor screen where it modulates erythropoiesis (Bai et al. 2010), and oligodendrocyte differentiation (Kim et al. 2012). The identification of a zebrafish $c d c 73$ mutant may provide an attractive device for creating a zebrafish model of parathyroid tumors (Bourque \& Houvras 2011).
The potential role of surrounding tissue microenvironment in the pathogenesis of medullary thyroid cancer (MTC) may be investigated using zebrafish as model. In humans C-cells are dispersed throughout the thyroid parenchyma, whereas in zebrafish this cell type arises from the ultimobranchial bodies but does not come into contact with thyroid follicles. Malignant transformation of C-cells by RET oncogene leads to MTC in humans, but the role of surrounding follicular thyroid cells is presently unknown. So it would be interesting to determine the disease phenotype emerging in species where C-cells are not colocalized with thyroid epithelial cells (Bourque \& Houvras 2011). Indeed, thyroid epithelial cells are able to synthesize extracellular matrix components in mammals, and it has been postulated that extracellular matrix may have a role in the pathogenesis and progression of MTC (Lekmine et al. 1999).

Zebrafish embryos represent an interesting model to study the factors and signaling events involved in pancreatic endocrine cell differentiation, proliferation, and carcinogenesis (Tehrani \& Lin 2011). It is possible to perform chemical screens in transgenic zebrafish embryos aimed to identify compounds that modulate $\beta$-cell differentiation and proliferation (Hesselson et al. 2009, Rovira et al. 2011), providing determinant information to identify novel therapies for diabetes mellitus and pancreatic NETs. In this regard, when oncogenic human MYCN was expressed under the control of the zebrafish $m y o D$ promoter, that drives gene expression in pancreatic neuroendocrine $\beta$-cells, neurons, and muscle cells, a small number of the transgenic fish developed a neuroendocrine carcinomas between 4 and 6 months of age (Yang et al. 2004). It is well known that the $c-M Y C$ proto-oncogene is implicated in human pancreatic $\beta$-cells growth and tumorigenesis (Pelengaris \& Khan 2001). This study suggested that mycn, a relative of $c-M Y C$, may function in a similar manner in zebrafish (Yang et al. 2004). In future, the generation of a stable transgenic line expressing MYCN in the pancreas may provide a power drug-screening platform for pancreatic NET.

The MYC/MAX/MXD1 network has also a critical role in the development of tumors of neural crest origin, such as neuroblastoma, pheochromocytomas, and paragangliomas (Cascon \& Robledo 2012). Zhu et al. (2012) have generated a transgenic zebrafish model in which overexpression of human $M Y C N$ and activated anaplastic lymphoma kinase $(A L K)$ genes in peripheral sympathetic nervous system develops tumors in the fish

Published by Bioscientifica Ltd. 
analog of the adrenal medulla that closely resemble human neuroblastoma.

With its genomic versatility and amenability to genetic and experimental manipulation, the zebrafish model may provide relevant insight into the study of hereditary disorders, including NETs as part of a hereditary syndrome.

Multiple endocrine neoplasia type 1 (MEN1) is an autosomal dominant disorder characterized by the development of tumors of pituitary, parathyroid glands, and endocrine pancreas. The responsible gene MEN1 encodes a 610-amino acid protein in humans, called menin. The gene is highly conserved in all vertebrate species including fish. Zebrafish menin is a 617-amino acid protein with $75 \%$ similarity to human menin and the region spanning residues $41-322$ is highly conserved (83\% homology). Amino acids affected by inactivating missense mutations in MEN1 patients in this region are completely conserved between human and zebrafish. Such a high conservation strongly supports the functional relevance of this region (Khodaei et al. 1999). Analysis of the database of zebrafish mutants available from the zebrafish Information Network (http://zfin.org/action/ fish/search) does not show any zebrafish men1 mutant, but the generation of zebrafish mutants for this gene through the previously reported technologies may open novel interesting perspectives.

MEN2 is a hereditary disorder consisting of three syndromes: MEN2A, MEN2B, and familial MTC. These syndromes, due to germline-activating mutations of the RET proto-oncogene, result in the development of MTC and other tumors embryologically arising from the neural crest (Vitale et al. 2001). Human RET gene encodes two isoforms, termed RET9 and RET51. Zebrafish ret is capable of encoding both isoforms. The zebrafish ret9 amino acid sequence is identical to human RET9, and zebrafish ret51 sequence shows significant sequence homology to human RET51, with $67 \%$ amino acid identity (Marcos-Gutierrez et al. 1997; Lucini et al. 2011). The exons encoding the tyrosine kinase domain are highly conserved from humans to zebrafish (Fisher et al. 2006). In zebrafish, ret signaling is crucial for the development of the enteric nervous system as in humans (Burzynski et al. 2009). Perturbation of ret and $g d n f$ by morpholino knockdown resulted in a complete loss of the zebrafish enteric nervous system (Burzynski et al. 2009). In addition, neural crest cells can be directly visualized in live fish by using transgenic lines that express GFP in the enteric neurons, such as the FoxD3:GFP transgenic line (Field et al. 2009). Therefore, zebrafish represents an interesting genetic model to study Hirschsprung's disease, generally associated with lack of RET function (Burzynski et al. 2009). Newly developed Ret mutants in zebrafish, harboring activating mutations similar to those found in patients with MEN2, could provide relevant information toward understanding the mechanisms involved in this disease and could offer a powerful platform for drug screening.

A continuum of MEN is represented by the Von Hippel-Lindau (VHL) disease, an autosomal dominant genetic condition that results in a constellation of cysts and extensively vascularized tumors, including several NETs (pheochromocytomas and pancreatic NETs; Richard et al. 2013). Germline-inactivating mutations in the VHL gene cause this syndrome. The main function of $V H L$ as tumor suppressor is to negatively regulate hypoxiainducible mRNAs, including those encoding VEGF, erythropoietin, platelet-derived growth factor (PDGF), and glucose-transporter GLUT1. VHL is involved in the degradation by the proteasome of the hypoxia-inducible transcription factor HIF- $1 \alpha$. HIF- $1 \alpha$ contributes to form transcriptional complex responsible for the activation of genes involved in angiogenesis, metabolism, and cell proliferation. In sum, the loss of VHL facilitates HIF accumulation that accounts for the excessive vascularization observed in VHL-related lesions and the development of tumors (Richard et al. 2013). In zebrafish the Vhl-Hif axis is highly conserved (Kajimura et al. 2006). vhl exhibits proangiogenic and tumor suppressor functions. Indeed, zebrafish vhl mutants develop several key aspects of the human disease condition, including activation of the Hif signaling pathway, severe pathological neovascularization, macular edema, pronephric abnormalities, and polycythemia (van Rooijen et al. 2010, 2011). Heterozygous $v h l$ zebrafish, upon exposure to dimethylbenzanthracene, exhibited an increase in the occurrence of hepatic and intestinal tumors (Santhakumar et al. 2012). Interestingly, Vhl/Hif signaling can be evaluated in vivo in the zebrafish $\mathrm{Tg}$ (phd3::EGFP) line expressing enhanced GFP (EGFP) driven by prolyl hydroxylase 3 (phd3) promoter/regulatory elements. Since phd3 is strongly induced by the Vhl activation (Santhakumar et al. 2012), the expression of $v h l$ mutants in the reporter zebrafish $\mathrm{Tg}$ (phd3::EGFP) line may represent a unique platform for the identification of new pathways involved in the development of VHL-associated neoplasms, including NETs. These models could be also helpful for chemical genetic screens aimed at identifying novel anti-angiogenic agents that are able to suppress HIF activity.

Published by Bioscientifica Ltd. 
Neurofibromatosis type 1 is a human genetic disorder characterized by café-au-lait macules and the growth of benign and malignant tumors involving the peripheral and CNS and NETs (pheochromocytoma, paragangliomas, gastroenteropancreatic-NETs). Inactivating mutations of NF1 gene have been linked to neurofibromatosis type 1 . Neurofibromin, the product of NF1, serves as a suppressor of the RAS activity (Laycock-van Spyk et al. 2011). Two zebrafish orthologs ( $n f 1 a$ and $n f 1 b$ ) are highly homologous to human NF1 (about 84\% identity). A zebrafish model of NF1 deficiency has been recently generated through stable mutant $n f 1$ zebrafish lines, using both zinc-finger nuclease and TILLING strategies (Shin et al. 2012). Zebrafish mutants lacking neurofibromin reveal abnormal patterning of the melanophores that compose the lateral stripes and are predisposed to tumor formation, a phenotype not very different from that reported in human neurofibromatosis type 1 (Shin et al. 2012). This zebrafish model represents an attractive tool to elucidate how NF1 mutations contribute to phenotypes and the mechanisms underlying the tissue-selectivity of tumors.

Tuberous sclerosis complex (TSC) is an autosomal dominant disorder, characterized by the development of multiple hamartomas, and occasionally by NETs. This disorder is caused by loss-of-function mutations of the TSC1 or the TSC2 genes, which code for the proteins hamartin and tuberin respectively. Hamartin and tuberin constitute a tumor suppressor complex that negatively modulates mammalian target of rapamycin (mTOR) signaling, a critical pathway in the regulation of cell proliferation and angiogenesis in several tumors, notably in NETs (Dworakowska \& Grossman 2009). Kim et al. (2011) developed a model system of TSC by introducing a premature stop codon in the zebrafish $t s c 2$ gene. $t s c 2$ homozygous mutant zebrafish exhibited several characteristics of TSC, including hamartoma formation in the brain and activation of TOR pathway (Kim et al. 2011). A similar model of TSC has been generated placing a heterozygous mutation of the $t s c 2$ gene in a $p 53$ mutant zebrafish. tsc2; p53 mutants developed multiorgan malignancies with increased expression of Hif1- $\alpha$, Hif2- $\alpha$ and Vegf-c, TOR activation and a conspicuous angiogenesis. Interestingly, mTOR inhibitor rapamycin significantly reduced tumor proliferation and vascularization (Kim et al. 2013). This zebrafish model would clarify most of the mechanisms contributing to tumorigenesis and mediated by dysregulation of the Tsc-TOR pathway. Another advantage of this model is its ability to accommodate large-scale anticancer drug screening for new molecules with a potential inhibitory activity toward Tsc-TOR signaling, representing a promising tool in the treatment of NETs.

\section{The zebrafish/tumor xenograft angiogenesis assay in NETs: preliminary data}

Angiogenesis has a critical role in the development of the tumor. Indeed, the formation of new vessels facilitates tumor metastasis and provides tumor cells with oxygen and nutrients, all essential factors to sustain the tumor growth. Most NETs have a highly diffuse vascularization. In fact, NETs typically produce a variety of proangiogenic cytokines and growth factors, including several members of VEGF, FGF, PDGF, epidermal growth factor (EGF), and insulin-like growth factor (IGF) families (Teule \& Casanovas 2012, Scoazec 2013).

For the vast majority of tumors, the blood vessel density represents a prognostic indicator of survival and metastatic potential. In fact, tumors with high vascular density have a higher incidence of metastasis than poorly vascularized tumors. On the other hand, a paradoxical situation ('The neuroendocrine paradox') emerged in pancreatic NETs. In these tumors intratumoral microvascular density is higher in benign lesions than in carcinomas. Surprisingly, in malignant tumors microvascular density seems to be a favorable parameter, associated with a prolonged survival (Scoazec 2013). In addition, direct or indirect signs of proangiogenic response and hypoxia are expressed more clearly in high-grade than in low-grade tumors. To explain these observations, it has been postulated that in pancreatic NETs: i) the density of the vascular network is a marker of differentiation rather than a marker of aggressiveness; ii) angiogenesis is not tightly connected to metastatic properties. Therefore the most vascularized pancreatic NETs appear to be the most differentiated and the less angiogenic neoplasms (Scoazec 2013). In this regard, several issues need to be still addressed. As the 'neuroendocrine paradox' has been demonstrated only in pancreatic NETs, it remains to be verified whether it is translatable to the other types of NETs and to metastatic as well as to primary sites. These questions and a better knowledge of the mechanisms and regulation of tumor angiogenesis in NETs may be clinically highly relevant to determine the best antiangiogenic therapeutic strategy.

As mechanisms playing a role in tumor-host interactions are highly conserved between human and

Published by Bioscientifica Ltd. 
zebrafish (Tobia et al. 2013), and the process of angiogenesis is mechanistically similar in embryonic and tumor development, we decided to perform the xenotransplantation of human NET cancer cells into the subperidermal space of zebrafish embryos (Fig. 1). It has been previously demonstrated that inoculation of mammalian tumor cells in zebrafish embryos can induce a potent angiogenic response through the secretion of several growth factors (Nicoli et al. 2007). VEGF/FGF gradient produced by the tumor is able to guide the



\section{Figure 3}

Schematic representation of putative molecular pathways involved in tumor xenograft-mediated angiogenesis. VEGF production is stimulated in implanted tumor cells by the hypoxia and low $\mathrm{pH}$ of the tumor microenvironment together with activation of different receptors for common growth factors (FGF, PDGF, EGF, IGF, etc.). These receptors promote several signal transduction events (Ras-Raf-MEK-ERK and PI3K-AKT-mTOR) that control cell cycle, survival, and migration of tumor cells. In addition, human VEGF secreted by the implant stimulates cell proliferation, migration, and survival of zebrafish endothelial cells probably through the activation of PI3K-AKT-mTOR, src-NOs, and MAPK. These processes induce and drive the sprouting of blood vessels from the subintestinal vessels (SIV) toward the tumor. The interplay between numerous signaling pathways provides an accurate phenotypic specialization of endothelial cells.

A growing sprout consists of a tip cell that leads the developing vessel and extends philopodia during the migration and several stalk cells that form the vessel trunk. Molecular mechanisms that control the specification of tip and stalk cells are very conserved during the evolution of vertebrates and depend on the interaction between Notch and VEGF signaling (Siekmann \& Lawson 2007). Hypoxia-driven VEGF signaling induces expression of the Notch ligand Delta-like-4 (DII4) in tip cells. Then, the interaction between DIl4 and Notch receptor activates Notch pathway in adjacent endothelial cells, leading to the reduction of VEGF receptor 2 (VEGFR2) expression and thereby promoting the stalk cell phenotype (Siekmann \& Lawson 2007). These processes are highly activated in neuroendocrine tumors and can be counteracted by the stimulation of somatostatin receptors (SSTRs) expressed in both neuroendocrine tumors cells and human endothelial cells of peritumoral vessels. SSTRs are conserved through evolution. However, the expression and the function of these receptors in peritumoral vessels need to be explored in zebrafish.

Published by Bioscientifica Ltd. 
sprouting of new blood vessels from the close vascular network (SIV). This is a complex phenomenon involving several pathways and mechanisms that are schematically illustrated in Fig. 3. Interestingly, most of these pathways deregulated in zebrafish/tumor xenograft model are commonly activated in human NETs.

We have recently developed a system to study NETmediated angiogenesis (Vitale G, Gaudenzi G, Dicitore A, Cotelli F and Persani, 2013, unpublished observations), based on the injection of two human NET cell lines (TT, a human MTC cell line and DMS79, a human small-cell lung carcinoma cell line secreting ACTH) in $T g(\text { fli1:EGFP })^{y 1}$ zebrafish line that expresses EGFP under the control of the fli1 promoter (Fig. 1A and B). Both NET cell lines have been selected on the basis of strong proangiogenic capacity, related to the high production of VEGF (Lund et al. 2000, Petrangolini et al. 2006).

Starting from $24 \mathrm{hpi}$, we evaluated the ability of both tumor cell lines to induce the sprouting of new vessels from the SIV and the CCV (Fig. 4). While the control larvae injected with only phosphate buffered saline solution (PBS) did not display alterations of vascular network, the injection of TT and DMS79 cells line stimulated migration and growth of sprouting vessels from SIV and CCV toward grafted cells in a time-dependent manner (Fig. 4). Indeed, we observed new blood vessels that rapidly reached the graft and progressively surrounded and penetrated the tumor cells mass. A more intricate network of new blood vessels was observed in TT tumor-xenograft (Figs 4 and 5). In a temporal window of three days post injection, we observed that the neovascularization followed morphogenetic steps resembling physiological angiogenesis that occurs during embryonic development and in adult animals (Fig. 5A, B, C, D, E, and F). Indeed, in 24 and 48 hpi TT-grafted larvae we detected that endothelial cells leading the growing sprout have a 'tip phenotype', with long philopodia that probably explore molecular signals in the microenvironment of tumor cells (Fig. 5A, B, D, D', $\mathrm{E}$, and $\mathrm{E}^{\prime}$ ). Moreover, we observed that endothelial sprouts with tip cells were progressively converted in vessels (Fig. 5C, F, and $\mathrm{F}^{\prime}$ ) (Adams \& Alitalo 2007). Histological sections of 48 hpi TT-grafted larvae stained with wholemount alkaline phosphatase clearly showed that new vessels reached and penetrated the tumor mass (Fig. 5G, H, I, and J).

Somatostatin and dopamine receptors, as well as mTOR pathway, represent pivotal controllers of hormonal secretion, cell proliferation, and angiogenesis in human NETs (Gatto \& Hofland 2011). Indeed, somatostatin analogs, dopamine agonists, and mTOR inhibitors are
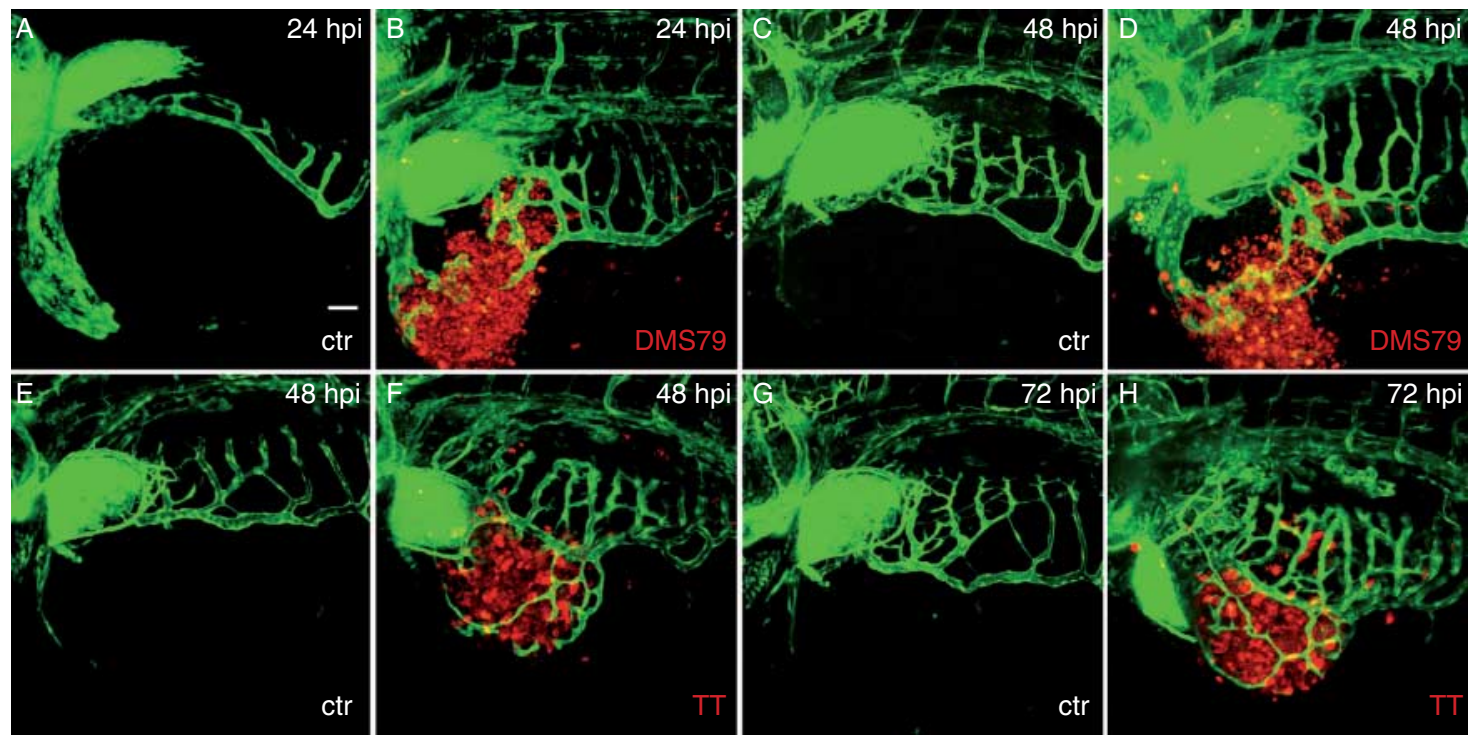

\section{Figure 4}

Neuroendocrine tumor (NET)-grafted cells stimulate angiogenesis in zebrafish larvae. Representative confocal microscopic images of $48 \mathrm{hpf}$ $T g(f l i 1: E G F P)^{y 1}$ zebrafish larvae implanted with red fluorescence-stained DMS79 ( $B$ and $D$ ) and TT ( $F$ and H) cells. After 24 ( $A$ and B), 48 (C, D, E, and F), and 72 hpi ( $G$ and $H$ ) larvae were embedded in low-melting agarose and the yolk region was observed by confocal microscopy. In comparison to

http://erc.endocrinology-journals.org DOI: $10.1530 / E R C-13-0388$ (c) 2014 Society for Endocrinology Printed in Great Britain
PBS-injected control larvae (A, C, E, and G), NET-grafted larvae showed vessels that sprout from the SIV and the $\operatorname{CCV}(B, D, F$, and $H)$. TT seemed to have a more robust proangiogenic activity ( $F$ and $H)$. All images are oriented so that rostral is to the left and dorsal is at the top. Scale bar, $50 \mu \mathrm{m}$.

Published by Bioscientifica Ltd. 

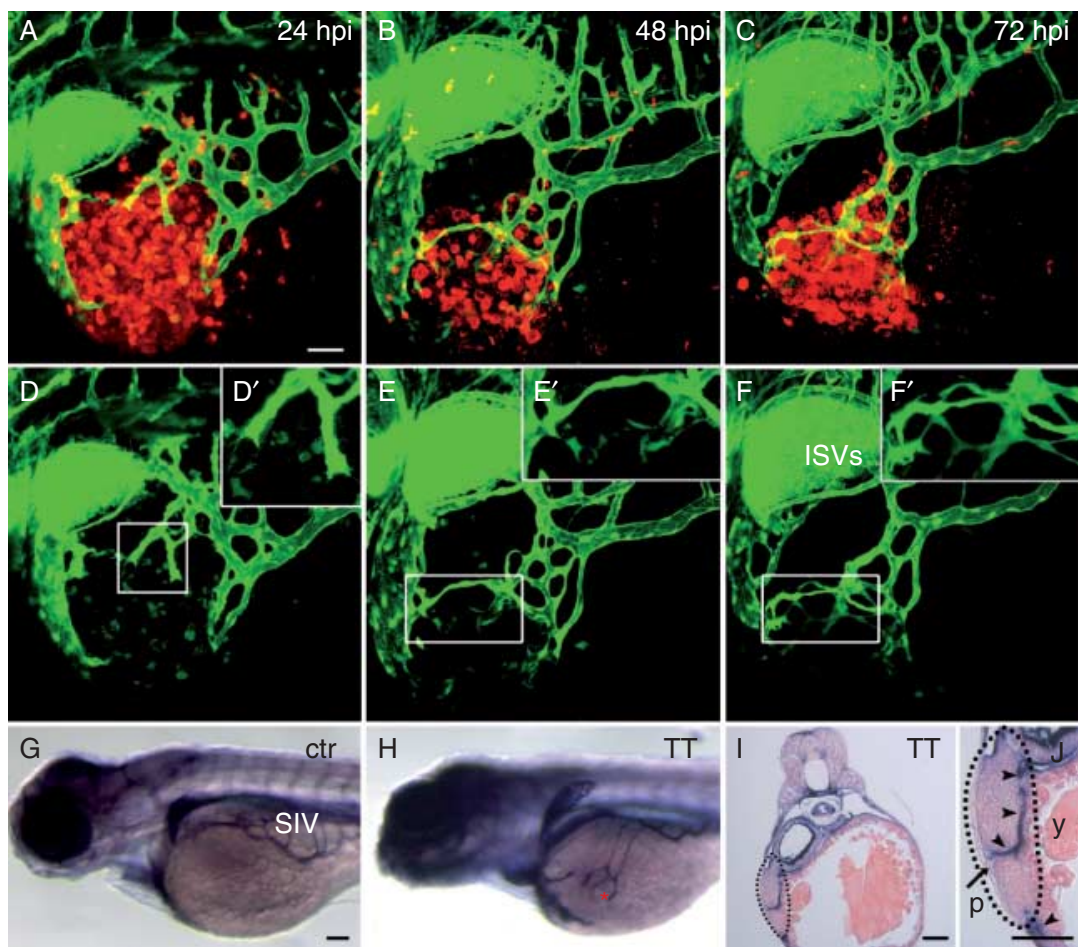

\section{Figure 5}

Progressive vascularization of tumor cells mass in TT tumor xenografts. Representative microscopic images of $48 \mathrm{hpf} T g(f l i 1: E G F P)^{y}{ }^{1}$ zebrafish larvae implanted with red fluorescence stained TT cells. The same TT grafted larva was observed by confocal microscopy $\left(A, B, C, D, D^{\prime}, E_{1}, E^{\prime}, F_{1}\right.$ and $F^{\prime}$ ) at 24 ( $A$ and $D$ ), 48 ( $B$ and $E$ ), and 72 ( $C$ and $F$ ) hpi. Images in $A, B$, and $C$ showed sprouting vessels that progressively reached and surrounded red grafted cells. The red channel image was omitted in panels $D, D^{\prime}, E, E^{\prime}$, and $F$ to highlight the newly formed microvascular network. Digital magnification of boxed regions in $D, E$, and $F\left(D^{\prime}, E^{\prime}\right.$ and $\left.F^{\prime}\right)$ suggested that tumor xenograft mediated angiogenesis is a multistep process, in which endothelial sprouts with tip cells (cells with long philopodia in $D^{\prime}$ and $E^{\prime}$ )

currently used in the therapy of NETs (Faggiano et al. 2012, Ruscica et al. 2013).

Mammals have five somatostatin receptor genes, named SSTR1 through 5 (Olias et al. 2004), whereas zebrafish has eight SSTR genes: SSTR1, $-2 \mathrm{a},-2 \mathrm{~b},-3 \mathrm{a},-3 \mathrm{~b}$, $-5 \mathrm{a},-5 \mathrm{~b}$, and -6 (Ocampo Daza et al. 2012). Comparative genomic analyses suggested that SSTRs family arose from a series of gene duplication events throughout the course of vertebrate evolution. In particular, the increase in SSTRs family members could be the result of the basal vertebrate whole-genome duplications and subsequently the teleostspecific genome duplication. One of the teleost receptors gene, sstr6, represents an ancestral vertebrate subtype that has been lost in tetrapods, while $s$ str 4 sequences could not be identified in teleosts (Ocampo Daza et al. 2012). Zebrafish and human amino acidic SSTR sequences showed a high degree of identity ranging $50-80 \%$. were progressively converted in vessels. Alkaline phosphatase staining was performed on $\mathbf{4 8} \mathrm{hpi}$ control (G) and TT grafted larvae (H, red asterisk indicates the position of TT cells). Transverse histological sections (I and J) of alkaline phosphatase-stained TT-grafted larvae displayed that vessels penetrated in the tumor mass. Dashed areas in I and J (original magnification of tumor mass) showed the position of tumor cells between the periderm ( $p$ ) and the yolk (y). Arrowheads in J indicate neoformed vessels surrounding and penetrating the tumor implant. Images from A to $\mathrm{H}$ are oriented so that rostral is to the left and dorsal is at the top. Scale bar, $50 \mu \mathrm{m}$

In mammals, five-specific dopamine receptors have been characterized and are classified into two subgroups: D1-like (D1, D5) and D2-like receptors (D2, D3, D4) (Ferone et al. 2009). In zebrafish, 8 dopamine receptors have been cloned (Barreto-Valer et al. 2012): D1-like receptor (Drd1), which shares $71 \%$ amino acid identity to humans (Li et al. 2007); the D2-like receptors (Drd2a, Drd2b, Drd2c, Drd3, Drd4a, Drd4b, and Drd4rs), which show an amino acid identity with human sequence ranging 56-67\% (Boehmler et al. 2004, 2007).

Like its mammalian counterpart, the zebrafish TOR ortholog (zTOR) plays a central role in the regulation of cell proliferation and angiogenesis. Indeed, TOR is a highly conserved serine-threonine kinase that is a physiological target of embryonic growth-associated protein (EGAP) $\mathrm{N}$-terminal acetyltransferase complex during zebrafish development. Its role into angiogenesis is supported by

Published by Bioscientifica Ltd. 
several experimental evidences. Indeed, pharmacological inhibition of TOR with rapamycin leads to growth and vessel defects resembling the phenotypes of EGAP knockdown. Moreover, the overexpression of constitutively active TOR rescued normal vessel phenotype (Wenzlau et al. 2006).

Therefore, the zebrafish model may be exploited to investigate the molecular mechanisms underlying the SSTR-, dopamine receptor-, and TOR-dependent inhibition of NET tumor angiogenesis.

\section{Conclusions}

Only few models are currently available for NETs, probably due to the rare occurrence and heterogeneity of this group of neoplasms. These have been mainly developed in rodents and have been useful to understand the role of oncogenes or tumor suppressor genes involved in the development of various types of NETs (Pellegata et al. 2006). More recently another interesting NET model includes three-dimensional cell culture, a valuable method for drug screening due to its relevance in modeling the in vivo tumor size organization and microenvironment.

In this frame, our zebrafish/NET xenograft model may represent an attractive, fast, and technically simple model to study tumor-host microenvironment, to better characterize the multiple mechanisms of angiogenesis in NETs and to test in vivo the effects of new compounds (such as somatostatin-dopamine chimeras, dual PI3K/AKT/mTOR inhibitors, tyrosine-kinase inhibitors) on tumor angiogenesis. In addition, this model can potentially provide an exhaustive response to the unanswered questions related to the 'neuroendocrine paradox'.

In conclusion, there is reasonable hope that zebrafish can represent an optimal experimental model in NETs for drug screening and to elucidate molecular mechanisms involved in tumorigenesis and cancer progression.

\section{Declaration of interest}

The authors declare that there is no conflict of interest that could be perceived as prejudicing the impartiality of the review.

\section{Funding}

This research did not receive any specific grant from any funding agency in the public, commercial, or not-for-profit sector.

\section{References}

Adams RH \& Alitalo K 2007 Molecular regulation of angiogenesis and lymphangiogenesis. Nature Reviews. Molecular Cell Biology 8 464-478. (doi:10.1038/nrm2183)

Aflorei E, Chen C, McGonnell I, Fowkes R, Grossman A, Tapon N, Stanewsky R \& Korbonits M 2012 Development of novel AIP (aryl hydrocarbon receptor-interacting protein) gene study models using the fruitfly and the zebrafish. Endocrine Abstracts 29 P1334.

Amatruda JF, Shepard JL, Stern HM \& Zon LI 2002 Zebrafish as a cancer model system. Cancer Cell 1 229-231. (doi:10.1016/S1535-6108 (02)00052-1)

Bai X, Kim J, Yang Z, Jurynec MJ, Akie TE, Lee J, LeBlanc J, Sessa A, Jiang H, DiBiase A et al. 2010 TIF1 $\gamma$ controls erythroid cell fate by regulating transcription elongation. Cell 142 133-143. (doi:10.1016/j.cell.2010. 05.028)

Barreto-Valer K, Lopez-Bellido R, Macho Sanchez-Simon F \& Rodriguez RE 2012 Modulation by cocaine of dopamine receptors through miRNA133b in zebrafish embryos. PLOS ONE 7 e52701. (doi:10.1371/journal. pone.0052701)

Bedell VM, Wang Y, Campbell JM, Poshusta TL, Starker CG, Krug RG II, Tan W, Penheiter SG, Ma AC, Leung AY et al. 2012 In vivo genome editing using a high-efficiency TALEN system. Nature 491 114-118. (doi:10.1038/nature11537)

Bellipanni G, Murakami T \& Weinberg ES 2010 Molecular dissection of Otx1 functional domains in the zebrafish embryo. Journal of Cellular Physiology 222 286-293. (doi:10.1002/jcp.21944)

Bhaya D, Davison M \& Barrangou R 2011 CRISPR-Cas systems in bacteria and archaea: versatile small RNAs for adaptive defense and regulation. Annual Review of Genetics 45 273-297. (doi:10.1146/ annurev-genet-110410-132430)

Bill BR, Petzold AM, Clark KJ, Schimmenti LA \& Ekker SC 2009 A primer for morpholino use in zebrafish. Zebrafish 6 69-77. (doi:10.1089/zeb.2008. 0555)

Boehmler W, Obrecht-Pflumio S, Canfield V, Thisse C, Thisse B \& Levenson R 2004 Evolution and expression of D2 and D3 dopamine receptor genes in zebrafish. Developmental Dynamics 230 481-493. (doi:10.1002/dvdy.20075)

Boehmler W, Carr T, Thisse C, Thisse B, Canfield VA \& Levenson R 2007 D4 dopamine receptor genes of zebrafish and effects of the antipsychotic clozapine on larval swimming behaviour. Genes, Brain and Behavior 6 155-166. (doi:10.1111/j.1601-183X.2006.00243.x)

Bourque C \& Houvras Y 2011 Hooked on zebrafish: insights into development and cancer of endocrine tissues. Endocrine-Related Cancer 18 R149-R164. (doi:10.1530/ERC-11-0099)

Bricaire L, Odou MF, Cardot-Bauters C, Delemer B, North MO, Salenave S, Vezzosi D, Kuhn JM, Murat A, Caron P et al. 2013 Frequent large germline HRPT2 deletions in a French National cohort of patients with primary hyperparathyroidism. Journal of Clinical Endocrinology and Metabolism 98 E403-E408. (doi:10.1210/jc.2012-2789)

Burzynski G, Shepherd IT \& Enomoto H 2009 Genetic model system studies of the development of the enteric nervous system, gut motility and Hirschsprung's disease. Neurogastroenterology and Motility 21 113-127. (doi:10.1111/j.1365-2982.2008.01256.x)

Carpten JD, Robbins CM, Villablanca A, Forsberg L, Presciuttini S, Bailey-Wilson J, Simonds WF, Gillanders EM, Kennedy AM, Chen JD et al. 2002 HRPT2, encoding parafibromin, is mutated in hyperparathyroidism-jaw tumor syndrome. Nature Genetics 32 676-680. (doi:10.1038/ng1048)

Cascon A \& Robledo M 2012 MAX and MYC: a heritable breakup. Cancer Research 72 3119-3124. (doi:10.1158/0008-5472.CAN-11-3891)

Cong L, Ran FA, Cox D, Lin S, Barretto R, Habib N, Hsu PD, Wu X, Jiang W, Marraffini LA et al. 2013 Multiplex genome engineering using CRISPR/Cas systems. Science 339 819-823. (doi:10.1126/science. 1231143) 
Dworakowska D \& Grossman AB 2009 Are neuroendocrine tumours a feature of tuberous sclerosis? A systematic review Endocrine-Related Cancer 16 45-58. (doi:10.1677/ERC-08-0142)

Faggiano A, Ramundo V, Dicitore A, Castiglioni S, Borghi MO, Severino R, Ferolla P, Crino L, Abbruzzese A, Sperlongano P et al. 2012 Everolimus is an active agent in medullary thyroid cancer: a clinical and in vitro study. Journal of Cellular and Molecular Medicine 16 1563-1572. (doi:10.1111/ j.1582-4934.2011.01438.x)

Feitsma H \& Cuppen E 2008 Zebrafish as a cancer model. Molecular Cancer Research 6 685-694. (doi:10.1158/1541-7786.MCR-07-2167)

Ferone D, Gatto F, Arvigo M, Resmini E, Boschetti M, Teti C, Esposito D \& Minuto F 2009 The clinical-molecular interface of somatostatin, dopamine and their receptors in pituitary pathophysiology. Journal of Molecular Endocrinology 42 361-370. (doi:10.1677/JME-08-0162)

Field HA, Kelley KA, Martell L, Goldstein AM \& Serluca FC 2009 Analysis of gastrointestinal physiology using a novel intestinal transit assay in zebrafish. Neurogastroenterology and Motility 21 304-312. (doi:10.1111/ j.1365-2982.2008.01234.x)

Fieramonti L, Bassi A, Foglia EA, Pistocchi A, D'Andrea C, Valentini G, Cubeddu R, De Silvestri S, Cerullo G \& Cotelli F 2012 Time-gated optical projection tomography allows visualization of adult zebrafish internal structures. PLoS ONE 7 e50744. (doi:10.1371/journal.pone.0050744)

Fisher S, Grice EA, Vinton RM, Bessling SL \& McCallion AS 2006 Conservation of RET regulatory function from human to zebrafish without sequence similarity. Science 312 276-279. (doi:10.1126/ science.1124070)

Gatto F \& Hofland LJ 2011 The role of somatostatin and dopamine D2 receptors in endocrine tumors. Endocrine-Related Cancer 18 R233-R251. (doi:10.1530/ERC-10-0334)

Ghotra VP, He S, de Bont H, van der Ent W, Spaink HP, van de Water B, Snaar-Jagalska BE \& Danen EH 2012 Automated whole animal bio-imaging assay for human cancer dissemination. PLOS ONE 7 e31281. (doi:10.1371/journal.pone.0031281)

Haldi M, Ton C, Seng WL \& McGrath P 2006 Human melanoma cells transplanted into zebrafish proliferate, migrate, produce melanin, form masses and stimulate angiogenesis in zebrafish. Angiogenesis 9 139-151. (doi:10.1007/s10456-006-9040-2)

Hesselson D, Anderson RM, Beinat M \& Stainier DY 2009 Distinct populations of quiescent and proliferative pancreatic $\beta$-cells identified by HOTcre mediated labeling. PNAS 106 14896-14901. (doi:10.1073/ pnas.0906348106)

Hwang WY, Fu Y, Reyon D, Maeder ML, Tsai SQ, Sander JD, Peterson RT, Yeh JR \& Joung JK 2013 Efficient genome editing in zebrafish using a CRISPRCas system. Nature Biotechnology 31 227-229. (doi:10.1038/nbt.2501)

Igreja S, Chahal HS, King P, Bolger GB, Srirangalingam U, Guasti L, Chapple JP, Trivellin G, Gueorguiev M, Guegan K et al. 2010 Characterization of aryl hydrocarbon receptor interacting protein (AIP) mutations in familial isolated pituitary adenoma families. Human Mutation 31 950-960. (doi:10.1002/humu.21292)

Isogai S, Horiguchi M \& Weinstein BM 2001 The vascular anatomy of the developing zebrafish: an atlas of embryonic and early larval development. Developmental Biology 230 278-301. (doi:10.1006/ dbio.2000.9995)

Kajimura S, Aida K \& Duan C 2006 Understanding hypoxia-induced gene expression in early development: in vitro and in vivo analysis of hypoxiainducible factor 1-regulated zebra fish insulin-like growth factor binding protein 1 gene expression. Molecular and Cellular Biology 26 1142-1155. (doi:10.1128/MCB.26.3.1142-1155.2006)

Khodaei S, O’Brien KP, Dumanski J, Wong FK \& Weber G 1999 Characterization of the MEN1 ortholog in zebrafish. Biochemical and Biophysical Research Communications 264 404-408. (doi:10.1006/ bbrc.1999.1529)

Kim SH, Speirs CK, Solnica-Krezel L \& Ess KC 2011 Zebrafish model of tuberous sclerosis complex reveals cell-autonomous and non-cellautonomous functions of mutant tuberin. Disease Models \& Mechanisms 4 255-267. (doi:10.1242/dmm.005587)
Kim S, Kim JD, Chung AY, Kim HS, Kim YS, Kim MJ, Koun S, Lee YM, Rhee M, Park HC et al. 2012 Antagonistic regulation of PAF1C and p-TEFb is required for oligodendrocyte differentiation. Journal of Neuroscience $\mathbf{3 2}$ 8201-8207. (doi:10.1523/JNEUROSCI.5344-11.2012)

Kim SH, Kowalski ML, Carson RP, Bridges LR \& Ess KC 2013 Heterozygous inactivation of tsc2 enhances tumorigenesis in p53 mutant zebrafish. Disease Models \& Mechanisms 6 925-933. (doi:10.1242/dmm.011494)

Konantz M, Balci TB, Hartwig UF, Dellaire G, Andre MC, Berman JN \& Lengerke C 2012 Zebrafish xenografts as a tool for in vivo studies on human cancer. Annals of the New York Academy of Sciences 1266 124-137. (doi:10.1111/j.1749-6632.2012.06575.x)

Laycock-van Spyk S, Thomas N, Cooper DN \& Upadhyaya M 2011 Neurofibromatosis type 1-associated tumours: their somatic mutational spectrum and pathogenesis. Human Genomics 5 623-690. (doi:10.1186/ 1479-7364-5-6-623)

Lee LM, Seftor EA, Bonde G, Cornell RA \& Hendrix MJ 2005 The fate of human malignant melanoma cells transplanted into zebrafish embryos: assessment of migration and cell division in the absence of tumor formation. Developmental Dynamics 233 1560-1570. (doi:10.1002/dvdy.20471)

Lekmine F, Feracci H, Milhaud G, Treilhou-Lahille F \& Jeanne N 1999 Expression of laminin-2 by normal and neoplastic rat $\mathrm{C}$ cells during the development of medullary thyroid carcinoma. Virchows Archiv $\mathbf{4 3 4}$ 325-332. (doi:10.1007/s004280050348)

Li P, Shah S, Huang L, Carr AL, Gao Y, Thisse C, Thisse B \& Li L 2007 Cloning and spatial and temporal expression of the zebrafish dopamine D1 receptor. Developmental Dynamics 236 1339-1346. (doi:10.1002/ dvdy.21130)

Lieschke GJ \& Currie PD 2007 Animal models of human disease: zebrafish swim into view. Nature Reviews. Genetics 8 353-367. (doi:10.1038/ nrg2091)

Liu S \& Leach SD 2011 Zebrafish models for cancer. Annual Review of Pathology 6 71-93. (doi:10.1146/annurev-pathol-011110-130330)

Liu TX, Zhou Y, Kanki JP, Deng M, Rhodes J, Yang HW, Sheng XM, Zon LI \& Look AT 2002 Evolutionary conservation of zebrafish linkage group 14 with frequently deleted regions of human chromosome 5 in myeloid malignancies. PNAS 99 6136-6141. (doi:10.1073/pnas.072560099)

Liu NA, Jiang H, Ben-Shlomo A, Wawrowsky K, Fan XM, Lin S \& Melmed S 2011 Targeting zebrafish and murine pituitary corticotroph tumors with a cyclin-dependent kinase (CDK) inhibitor. PNAS 108 8414-8419. (doi:10.1073/pnas.1018091108)

Lohr H \& Hammerschmidt M 2011 Zebrafish in endocrine systems: recent advances and implications for human disease. Annual Review of Physiology 73 183-211. (doi:10.1146/annurev-physiol-012110-142320)

Lucini C, D'Angelo L, Patruno M, Mascarello F, de Girolamo P \& Castaldo L 2011 GDNF family ligand RET receptor in the brain of adult zebrafish. Neuroscience Letters 502 214-218. (doi:10.1016/j.neulet.2011.07.047)

Lund EL, Thorsen C, Pedersen MW, Junker N \& Kristjansen PE 2000 Relationship between vessel density and expression of vascular endothelial growth factor and basic fibroblast growth factor in small cell lung cancer in vivo and in vitro. Clinical Cancer Research 6 4287-4291.

Ma AC, Lee HB, Clark KJ \& Ekker SC 2013 High efficiency in vivo genome engineering with a simplified 15-RVD GoldyTALEN design. PLOS ONE 8 e65259. (doi:10.1371/journal.pone.0065259)

Malafoglia V, Bryant B, Raffaeli W, Giordano A \& Bellipanni G 2013 The zebrafish as a model for nociception studies. Journal of Cellular Physiology 228 1956-1966. (doi:10.1002/jcp.24379)

Marcos-Gutierrez CV, Wilson SW, Holder N \& Pachnis V 1997 The zebrafish homologue of the ret receptor and its pattern of expression during embryogenesis. Oncogene 14 879-889. (doi:10.1038/sj.onc.1201048)

Marques IJ, Weiss FU, Vlecken DH, Nitsche C, Bakkers J, Lagendijk AK, Partecke LI, Heidecke CD, Lerch MM \& Bagowski CP 2009 Metastatic behaviour of primary human tumours in a zebrafish xenotransplantation model. BMC Cancer 9 128. (doi:10.1186/1471-2407-9-128) 
Mimeault M \& Batra SK 2013 Emergence of zebrafish models in oncology for validating novel anticancer drug targets and nanomaterials. Drug Discovery Today 18 128-140. (doi:10.1016/j.drudis.2012.08.002)

Moens CB, Donn TM, Wolf-Saxon ER \& Ma TP 2008 Reverse genetics in zebrafish by TILLING. Briefings in Functional Genomics \& Proteomics 7 454-459. (doi:10.1093/bfgp/eln046)

Moore FE \& Langenau DM 2012 Through the looking glass: visualizing leukemia growth, migration, and engraftment using fluorescent transgenic zebrafish. Advances in Hematology 2012478164. (doi:10.1155/2012/478164)

Moro E, Vettori A, Porazzi P, Schiavone M, Rampazzo E, Casari A, Ek O, Facchinello N, Astone M, Zancan I et al. 2013 Generation and application of signaling pathway reporter lines in zebrafish. Molecular Genetics and Genomics 288 231-242. (doi:10.1007/s00438-013-0750-z)

Nicoli S \& Presta M 2007 The zebrafish/tumor xenograft angiogenesis assay. Nature Protocols 2 2918-2923. (doi:10.1038/nprot.2007.412)

Nicoli S, Ribatti D, Cotelli F \& Presta M 2007 Mammalian tumor xenografts induce neovascularization in zebrafish embryos. Cancer Research $\mathbf{6 7}$ 2927-2931. (doi:10.1158/0008-5472.CAN-06-4268)

Ocampo Daza D, Sundstrom G, Bergqvist CA \& Larhammar D 2012 The evolution of vertebrate somatostatin receptors and their gene regions involves extensive chromosomal rearrangements. BMC Evolutionary Biology 12 231. (doi:10.1186/1471-2148-12-231)

Olias G, Viollet C, Kusserow H, Epelbaum J \& Meyerhof W 2004 Regulation and function of somatostatin receptors. Journal of Neurochemistry $\mathbf{8 9}$ 1057-1091. (doi:10.1111/j.1471-4159.2004.02402.x)

Pelengaris S \& Khan M 2001 Oncogenic co-operation in $\beta$-cell tumorigenesis. Endocrine-Related Cancer 8 307-314. (doi:10.1677/erc.0.0080307)

Pellegata NS, Quintanilla-Martinez L, Siggelkow H, Samson E, Bink K, Hofler H, Fend F, Graw J \& Atkinson MJ 2006 Germ-line mutations in p27Kip1 cause a multiple endocrine neoplasia syndrome in rats and humans. PNAS 103 15558-15563. (doi:10.1073/pnas.0603877103)

Petrangolini G, Cuccuru G, Lanzi C, Tortoreto M, Belluco S, Pratesi G, Cassinelli G \& Zunino F 2006 Apoptotic cell death induction and angiogenesis inhibition in large established medullary thyroid carcinoma xenografts by Ret inhibitor RPI-1. Biochemical Pharmacology 72 405-414. (doi:10.1016/j.bcp.2006.05.002)

Pichler FB, Laurenson S, Williams LC, Dodd A, Copp BR \& Love DR 2003 Chemical discovery and global gene expression analysis in zebrafish. Nature Biotechnology 21 879-883. (doi:10.1038/nbt852)

Pistocchi A, Gaudenzi G, Carra S, Bresciani E, Del Giacco L \& Cotelli F 2008 Crucial role of zebrafish prox1 in hypothalamic catecholaminergic neurons development. BMC Developmental Biology 8 27. (doi:10.1186/ 1471-213X-8-27)

Porazzi P, Calebiro D, Benato F, Tiso N \& Persani L 2009 Thyroid gland development and function in the zebrafish model. Molecular and Cellular Endocrinology 312 14-23. (doi:10.1016/j.mce.2009.05.011)

Quaife NM, Watson O \& Chico TJ 2012 Zebrafish: an emerging model of vascular development and remodelling. Current Opinion in Pharmacology 12 608-614. (doi:10.1016/j.coph.2012.06.009)

Rampazzo E, Persano L, Pistollato F, Moro E, Frasson C, Porazzi P Della Puppa A, Bresolin S, Battilana G, Indraccolo S et al. 2013 Wnt activation promotes neuronal differentiation of glioblastoma. Cell Death \& Disease 4 e500. (doi:10.1038/cddis.2013.32)

Richard S, Gardie B, Couve S \& Gad S 2013 Von Hippel-Lindau: how a rare disease illuminates cancer biology. Seminars in Cancer Biology 23 26-37. (doi:10.1016/j.semcancer.2012.05.005)

Rios Y, Melmed S, Lin S \& Liu NA 2011 Zebrafish usp39 mutation leads to rb1 mRNA splicing defect and pituitary lineage expansion. PLoS Genetics 7 e1001271. (doi:10.1371/journal.pgen.1001271)

van Rooijen E, Voest EE, Logister I, Bussmann J, Korving J, van Eeden FJ, Giles RH \& Schulte-Merker S 2010 von Hippel-Lindau tumor suppressor mutants faithfully model pathological hypoxia-driven angiogenesis and vascular retinopathies in zebrafish. Disease Models \& Mechanisms 3 343-353. (doi:10.1242/dmm.004036) van Rooijen E, Santhakumar K, Logister I, Voest E, Schulte-Merker S, Giles R \& van Eeden F 2011 A zebrafish model for VHL and hypoxia signaling. Methods in Cell Biology 105 163-190.

Rovira M, Huang W, Yusuff S, Shim JS, Ferrante AA, Liu JO \& Parsons MJ 2011 Chemical screen identifies FDA-approved drugs and target pathways that induce precocious pancreatic endocrine differentiation. PNAS 108 19264-19269. (doi:10.1073/pnas.1113081108)

Ruscica M, Arvigo M, Steffani L, Ferone D \& Magni P 2013 Somatostatin, somatostatin analogs and somatostatin receptor dynamics in the biology of cancer progression. Current Molecular Medicine 13 555-571. (doi:10.2174/1566524011313040008)

Santhakumar K, Judson EC, Elks PM, McKee S, Elworthy S, van Rooijen E, Walmsley SS, Renshaw SA, Cross SS \& van Eeden FJ 2012 A zebrafish model to study and therapeutically manipulate hypoxia signaling in tumorigenesis. Cancer Research 72 4017-4027. (doi:10.1158/0008-5472. CAN-11-3148)

Santoriello C \& Zon LI 2012 Hooked! Modeling human disease in zebrafish. Journal Clinical Investigation 122 2337-2343. (doi:10.1172/JCI60434)

Scoazec JY 2013 Angiogenesis in neuroendocrine tumors: therapeutic applications. Neuroendocrinology 97 45-56. (doi:10.1159/000338371)

Sharretts JM, Kebebew E \& Simonds WF 2010 Parathyroid cancer. Seminars in Oncology 37 580-590. (doi:10.1053/j.seminoncol.2010.10.013)

Shin J, Padmanabhan A, de Groh ED, Lee JS, Haidar S, Dahlberg S, Guo F, He S, Wolman MA, Granato M et al. 2012 Zebrafish neurofibromatosis type 1 genes have redundant functions in tumorigenesis and embryonic development. Disease Models \& Mechanisms 5 881-894. (doi:10.1242/dmm.009779)

Shive HR 2013 Zebrafish models for human cancer. Veterinary Pathology $\mathbf{5 0}$ 468-482. (doi:10.1177/0300985812467471)

Siekmann AF \& Lawson ND 2007 Notch signalling limits angiogenic cell behaviour in developing zebrafish arteries. Nature 445 781-784. (doi:10.1038/nature05577)

Stoletov K, Montel V, Lester RD, Gonias SL \& Klemke R 2007 Highresolution imaging of the dynamic tumor cell vascular interface in transparent zebrafish. PNAS 104 17406-17411. (doi:10.1073/pnas. 0703446104)

Taylor AM \& Zon LI 2009 Zebrafish tumor assays: the state of transplantation. Zebrafish 6 339-346. (doi:10.1089/zeb.2009.0607)

Tehrani Z \& Lin S 2011 Endocrine pancreas development in zebrafish. Cell Cycle 10 3466-3472. (doi:10.4161/cc.10.20.17764)

Teule A \& Casanovas O 2012 Relevance of angiogenesis in neuroendocrine tumors. Targeted Oncology 7 93-98. (doi:10.1007/ s11523-012-0217-x)

Tobia C, De Sena G \& Presta M 2011 Zebrafish embryo, a tool to study tumor angiogenesis. International Journal of Developmental Biology $\mathbf{5 5}$ 505-509. (doi:10.1387/ijdb.103238ct)

Tobia C, Gariano G, De Sena G \& Presta M 2013 Zebrafish embryo as a tool to study tumor/endothelial cell cross-talk. Biochimica et Biophysica Acta 1832 1371-1377. (doi:10.1016/j.bbadis.2013.01.016)

Topczewska JM, Postovit LM, Margaryan NV, Sam A, Hess AR, Wheaton WW, Nickoloff BJ, Topczewski J \& Hendrix MJ 2006 Embryonic and tumorigenic pathways converge via Nodal signaling: role in melanoma aggressiveness. Nature Medicine 12 925-932. (doi:10.1038/ $\mathrm{nm} 1448)$

Toro S, Wegner J, Muller M, Westerfield M \& Varga ZM 2009 Identification of differentially expressed genes in the zebrafish hypothalamicpituitary axis. Gene Expression Patterns 9 200-208. (doi:10.1016/j.gep. 2008.12.007)

Vitale G, Caraglia M, Ciccarelli A, Lupoli G, Abbruzzese A \& Tagliaferri P 2001 Current approaches and perspectives in the therapy of medullary thyroid carcinoma. Cancer 91 1797-1808. (doi:10.1002/10970142(20010501)91:9<1797::AID-CNCR1199>3.0.CO;2-P)

Vlotides G, Eigler T \& Melmed S 2007 Pituitary tumor-transforming gene: physiology and implications for tumorigenesis. Endocrinology Reviews 28 165-186. (doi:10.1210/er.2006-0042) 
Vogt A, Cholewinski A, Shen X, Nelson SG, Lazo JS, Tsang M \& Hukriede NA 2009 Automated image-based phenotypic analysis in zebrafish embryos. Developmental Dynamics 238 656-663. (doi:10.1002/dvdy.21892)

Wenner M 2009 The most transparent research. Nature Medicine 15 1106-1109. (doi:10.1038/nm1009-1106)

Wenzlau JM, Garl PJ, Simpson P, Stenmark KR, West J, Artinger KB, Nemenoff RA \& Weiser-Evans MC 2006 Embryonic growth-associated protein is one subunit of a novel N-terminal acetyltransferase complex essential for embryonic vascular development. Circulation Research 98 846-855. (doi:10.1161/01.RES.0000214539.86593.7a)

White R, Rose K \& Zon L 2013 Zebrafish cancer: the state of the art and the path forward. Nature Reviews. Cancer 13 624-636. (doi:10.1038/ nrc3589)
Yang HW, Kutok JL, Lee NH, Piao HY, Fletcher CD, Kanki JP \& Look AT 2004 Targeted expression of human MYCN selectively causes pancreatic neuroendocrine tumors in transgenic zebrafish. Cancer Research 64 7256-7262. (doi:10.1158/0008-5472. CAN-04-0931)

Yaniv K, Isogai S, Castranova D, Dye L, Hitomi J \& Weinstein BM 2006 Live imaging of lymphatic development in the zebrafish. Nature Medicine 12 711-716. (doi:10.1038/nm1427)

Zhu S, Lee JS, Guo F, Shin J, Perez-Atayde AR, KutokJL, Rodig SJ, Neuberg DS, Helman D, Feng H et al. 2012 Activated ALK collaborates with MYCN in neuroblastoma pathogenesis. Cancer Cell 21 362-373. (doi:10.1016/ j.ccr.2012.02.010)

Received in final form 15 November 2013

Accepted 28 November 2013

Made available online as an Accepted Preprint

29 November 2013 http://erc.endocrinology-journals.org DOI: 10.1530/ERC-13-0388
(C) 2014 Society for Endocrinology Printed in Great Britain
Published by Bioscientifica Ltd. 